\title{
PROSPECTIVE AND COMPARATIVE STUDY ON FUNCTIONAL OUTCOMES AFTER OPEN AND ARTHROSCOPIC REPAIR OF ROTATOR CUFF TEARS
}

Marco Antônio de Castro Veado', Rodrigo Simões Castilho ${ }^{2}$, Philipe Eduardo Carvalho Maia ${ }^{2}$, Alessandro Ulhôa Rodrigues ${ }^{3}$

\section{ABSTRACT}

Objective: To prospectively assess the surgical results from patients undergoing repairs to rotator cuff injuries via open and arthroscopic procedures, with regard to functional and clinical features, and by means of ultrasound examinations, and to compare occurrences of renewed tearing. Methods: Sixty patients underwent operations performed by the same surgeon (29 via open surgery and 31 via arthroscopy), to repair complete rotator cuff tears. The procedures were performed at Hospital Governor Israel Pinheiro (HGIP) and Mater Dei Hospital in Belo Horizonte, Minas Gerais, between August 2007 and February 2009. The patients were assessed functionally by means of the UCLA score before and after the operation, and magnetic resonance imaging was done before the operation. All the patients were reassessed at least 12 months after the operation, and an ultrasound examination was also performed at this time. Results: Out of the 29 patients who underwent open surgery, 27 (93.1\%) presented good or excellent results, with a mean UCLA score of 32 after the operation. Their mean follow-up was 14 months. Three patients presented renewed tearing on ultrasound, of whom one remained asymptomatic. Out of the 31 patients who underwent arthroscopic procedures, 29 (93.5\%) presented good or excellent results, with a mean UCLA score of 33 after the operation. Their mean follow-up was 19 months. Two patients presented renewed tearing, of whom one remained asymptomatic and one evolved with loosening of an anchor, with an unsatisfactory result. Conclusion: The repairs on rotator cuff injuries presented good results by means of both open surgery and arthroscopy, with similar functional results in the two groups and similar rates of renewed tearing.

Keywords - Rotator Cuff/injuries; Shoulder; Arthroscopy; Prospective Studies

The size and number of tendon involved vary ${ }^{(1-3,6-9)}$ and the clinical conditions also vary greatly, going from asymptomatic patients without any limitations to intensely painful conditions and significant functional impairment ${ }^{(1,2,8)}$. Rotator cuff injuries are the most important cause of shoulder pain in adults ${ }^{(10)}$.

The diagnosis of such injuries is essentially clinical, by means of a detailed anamnesis, in which the main symptom is pain, and through careful physical examination $^{(1,9)}$, along with functional tests and maneuvers to provoke irritation in the rotator

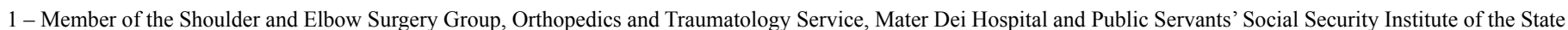
of Minas Gerais (IPSEMG) and São José University Hospital (FCMMG), Belo Horizonte, MG, Brazil.

2 - Third-year Resident in Orthopedics and Traumatology, Mater Dei Hospital, Belo Horizonte, MG, Brazil.

3 - Member of the Shoulder and Elbow Surgery Group, Orthopedics and Traumatology Service, Mater Dei Hospital, Belo Horizonte, MG, Brazil.

Work performed at Hospital Governador Israel Pinheiro and Mater Dei Hospital, Belo Horizonte, MG, Brazil.

Correspondence: Av. Celso Porfírio Machado 104, Bairro Belvedere, 30320-400 Belo Horizonte, MG, Brazil. E-mail: castrove@terra.com.br

Work received for publication: October 20, 2010; accepted for publication: March 22, 2011.

The authors declare that there was no conflict of interest in conducting this work 
cuff that are well known in orthopedic practice ${ }^{(1,8)}$. Complementary examinations such as radiography, arthrography and ultrasound can be used ${ }^{(1,11)}$, while magnetic resonance imaging (MRI) is the most accurate examination for measuring and locating the lesions, evaluating the quality of the tissues involved and scheduling the treatment ${ }^{(1,4,6,9)}$. The differential diagnosis with other pathological conditions of the shoulder, such as adhesive capsulitis and glenohumeral arthrosis, needs to be well established ${ }^{(1,9)}$.

There is still some controversy in the literature regarding the different forms of treatment ${ }^{(1,4,5)}$. Conservative treatment with medication and physiotherapy should be recommended in most cases, before indicating a more aggressive approach, especially among elderly people ${ }^{(1-4,6,10)}$. In surgical cases, the choices are open repair, mini-incision approaches and totally arthroscopic approaches, which all provide high rates of good results ${ }^{(1-6,8,12,13)}$. However, all these techniques present a risk of renewed tearing, which is the worst complication, especially in cases of large and extensive lesions $^{(6,8,13)}$.

The decision regarding which approach to use depends on several factors, such as age, lesion size and the surgeon's experience ${ }^{(2-4)}$.

\section{OBJECTIVES}

To prospectively assess the surgical results from patients undergoing repairs to rotator cuff injuries via open and arthroscopic procedures, with regard to functional and clinical features, and by means of ultrasound examinations, and to compare occurrences of renewed tearing.

\section{MATERIALS AND METHODS}

This was a comparative prospective study on 60 patients who underwent surgical treatment on a rotator cuff injury, either as an open or as an arthroscopic procedure. After the study had been approved by the Research Ethics Committee of Mater Dei Hospital, patients with a rotator cuff injury that had been operated by the same surgeon at the Orthopedics Service of Hospital Governador Israel Pinheiro and Hospital Mater Dei in Belo Horizonte, Minas Gerais, between August 2007 and February 2009, were included. The patients were divided into two groups: group I underwent open repair and group II underwent arthroscopic repair.

The following were exclusion criteria for this study: presence of extensive lesions (greater than five centimeters); presence of associated lesions (SLAP, Bankart etc); previous surgery on the same shoulder; presence of glenohumeral arthrosis; follow-up of less than 12 months; refusal to participate in the study; non-adherence or incorrect adherence to the protocol established; involvement in labor law issues.

Within each group, the patients were divided according to the size of the lesion, as follows: small lesions (smaller than one centimeter), medium-sized lesions (one to three centimeters) and large lesions (three to five centimeters) $^{(14,15)}$.

Out of 29 patients operated by means of an open procedure (group I), $26(89.7 \%$ ) were female. The mean age in group I was 58.7 years (range: $43-75$ years); 26 $(89.7 \%)$ were right-handed and in $25(86.2 \%)$ the side affected was the dominant side. Eight patients (27.6\%) reported that a traumatic event had occurred before the symptoms started. The mean preoperative UCLA score for this group was 17 (range: 8-27) (Table 1). Out of these 29 patients, three (10.3\%) presented small lesions, $12(41.4 \%)$ medium-sized lesions and $14(48.3 \%)$ large lesions. The mean duration of the follow-up was 14.1 months (range: 12 to 20 months).

Out of the 31 patients operated by means of arthroscopy (group II), 25 (80.6\%) were female. The mean age in group II was 58.9 years (range: $43-72$ years); 25 (80.6\%) were right-handed and in $27(87.1 \%)$ the side affected was the dominant side. Fifteen patients $(48.4 \%)$ reported that a traumatic event had occurred before the symptoms started. The mean preoperative UCLA score for this group was 15 (range: 8-28) (Table 2 ). Out of these 31 patients, seven $(22.6 \%)$ presented small lesions, $11(35.5 \%)$ medium-sized lesions and $13(41.9 \%)$ large lesions. The mean duration of the follow-up was 18.9 months (range: 12 to 35 months).

Before the operation, all the patients underwent radiography in true AP view, lateral scapular view with $20^{\circ}$ of caudal inclination and axillary view, MRI and UCLA (University of California in Los Angeles) assessment. All the patients included in this study did physiotherapy before the operation. This was a very specific sample of a group of patients belonging to the same population and with similar characteristics.

After the operation, after a minimum follow-up of 12 months, ultrasound examinations were performed on all the patients in order to ascertain whether any renewed tearing had occurred. All the patients were 
Table 1 - Patients in group I (open repair).

\begin{tabular}{|c|c|c|c|c|c|c|c|c|}
\hline Patient & Age & Sex & Trauma & \begin{tabular}{|c|} 
Time \\
$(\text { months) })^{*}$
\end{tabular} & $\begin{array}{l}\text { Size of } \\
\text { lesion }\end{array}$ & $\begin{array}{c}\text { UCLA } \\
\text { before op }\end{array}$ & $\begin{array}{c}\text { UCLA } \\
\text { after op }\end{array}$ & $\begin{array}{c}\text { Follow-up } \\
\text { (months) }\end{array}$ \\
\hline 01 & 55 & $F$ & No & 12 & Large & 23 & 35 & 18 \\
\hline 02 & 63 & $F$ & No & 24 & Medium & 21 & 35 & 14 \\
\hline 03 & 67 & $\mathrm{~F}$ & No & 60 & Medium & 23 & 35 & 12 \\
\hline 04 & 57 & $F$ & No & 18 & Medium & 10 & 27 & 20 \\
\hline 05 & 59 & $F$ & No & 18 & Large & 11 & 29 & 14 \\
\hline 06 & 66 & $F$ & Yes & 12 & Large & 21 & 34 & 12 \\
\hline 07 & 69 & $F$ & No & 36 & Large & 17 & 34 & 12 \\
\hline 08 & 50 & $F$ & No & 24 & Large & 14 & 33 & 12 \\
\hline 09 & 58 & M & No & 22 & Medium & 17 & 35 & 17 \\
\hline 10 & 75 & M & No & 12 & Large & 16 & 33 & 16 \\
\hline 11 & 62 & $F$ & Yes & 3 & Large & 13 & 32 & 12 \\
\hline 12 & 57 & $F$ & Yes & 5 & Large & 17 & 32 & 12 \\
\hline 13 & 54 & $F$ & No & 60 & Small & 15 & 35 & 14 \\
\hline 14 & 62 & $\mathrm{~F}$ & Yes & 5 & Medium & 12 & 20 & 16 \\
\hline 15 & 58 & $F$ & Yes & 4 & Large & 17 & 34 & 13 \\
\hline 16 & 69 & $F$ & No & 24 & Small & 22 & 35 & 16 \\
\hline 17 & 58 & $F$ & No & 36 & Large & 23 & 35 & 12 \\
\hline 18 & 51 & $F$ & No & 18 & Small & 8 & 35 & 13 \\
\hline 19 & 57 & $\mathrm{~F}$ & No & 12 & Medium & 27 & 33 & 15 \\
\hline 20 & 52 & $F$ & No & 24 & Medium & 18 & 32 & 17 \\
\hline 21 & 63 & $F$ & Yes & 6 & Medium & 16 & 35 & 16 \\
\hline 22 & 55 & $\mathrm{~F}$ & No & 24 & Medium & 21 & 35 & 14 \\
\hline 23 & 43 & $\mathrm{~F}$ & No & 36 & Large & 21 & 28 & 14 \\
\hline 24 & 54 & $F$ & Yes & 12 & Medium & 15 & 35 & 13 \\
\hline 25 & 46 & $\mathrm{~F}$ & Yes & 48 & Medium & 12 & 34 & 14 \\
\hline 26 & 56 & $\mathrm{~F}$ & No & 15 & Medium & 16 & 35 & 13 \\
\hline 27 & 53 & $\mathrm{~F}$ & Yes & 18 & Large & 25 & 33 & 13 \\
\hline 28 & 73 & $\mathrm{~F}$ & No & 60 & Large & 19 & 29 & 12 \\
\hline 29 & 60 & $M$ & No & 5 & Large & 17 & 35 & 13 \\
\hline
\end{tabular}

* Time elapsed between the start of the symptoms and the surgical procedure.

again assessed using the UCLA score at this time of evaluation.

The ultrasound examinations were performed using Toshiba linear transducer equipment of $7.5 \mathrm{MHz}$, by two professionals belonging to the same service.

\section{OPERATIVE TECHNIQUE}

Open repair: The patients were under general anesthesia in association with brachial plexus block, in the deckchair position. A superolateral access (for lesions of the supraspinatus alone or supra and infraspinatus) or a deltopectoral access (for subscapular
Table 2 - Patients in group II (arthroscopic repair).

\begin{tabular}{|c|c|c|c|c|c|c|c|c|}
\hline Patient & Age & Sex & Trauma & $\begin{array}{c}\text { Time } \\
\text { (months) }\end{array}$ & $\begin{array}{l}\text { Size of } \\
\text { lesion }\end{array}$ & $\begin{array}{c}\text { UCLA } \\
\text { before op }\end{array}$ & $\begin{array}{c}\text { UCLA } \\
\text { after op }\end{array}$ & $\begin{array}{c}\begin{array}{c}\text { Follow-up } \\
\text { (months) }\end{array} \\
\end{array}$ \\
\hline 1 & 52 & $F$ & Yes & 24 & Medium & 23 & 34 & 12 \\
\hline 2 & 58 & M & Yes & 5 & Large & 23 & 33 & 19 \\
\hline 3 & 59 & $F$ & Yes & 24 & Large & 14 & 35 & 33 \\
\hline 4 & 56 & $F$ & No & 6 & Medium & 16 & 33 & 13 \\
\hline 5 & 71 & $F$ & No & 240 & Large & 17 & 33 & 13 \\
\hline 6 & 48 & $F$ & No & 12 & Small & 16 & 32 & 13 \\
\hline 7 & 65 & $F$ & Yes & 2 & Medium & 20 & 33 & 18 \\
\hline 8 & 64 & M & Yes & 2 & Large & 19 & 35 & 35 \\
\hline 9 & 52 & $F$ & Yes & 7 & Large & 8 & 35 & 13 \\
\hline 10 & 52 & $\mathrm{~F}$ & Yes & 4 & Large & 13 & 33 & 15 \\
\hline 11 & 57 & $F$ & No & 24 & Small & 19 & 35 & 19 \\
\hline 12 & 64 & $F$ & No & 36 & Small & 10 & 16 & 15 \\
\hline 13 & 63 & $F$ & No & 24 & Large & 9 & 35 & 15 \\
\hline 14 & 43 & $F$ & No & 12 & Large & 9 & 34 & 23 \\
\hline 15 & 65 & $F$ & Yes & 4 & Medium & 21 & 33 & 12 \\
\hline 16 & 58 & $\mathrm{~F}$ & No & 24 & Small & 2 & 28 & 14 \\
\hline 17 & 69 & $\mathrm{~F}$ & No & 18 & Large & 21 & 35 & 24 \\
\hline 18 & 47 & $M$ & Yes & 6 & Large & 15 & 35 & 18 \\
\hline 19 & 71 & M & Yes & 1 & Large & 12 & 35 & 21 \\
\hline 20 & 57 & $F$ & No & 36 & Small & 17 & 35 & 31 \\
\hline 21 & 59 & $F$ & No & 18 & Small & 15 & 35 & 13 \\
\hline 22 & 53 & $F$ & Yes & 1 & Large & 19 & 33 & 17 \\
\hline 23 & 54 & $F$ & Yes & 6 & Medium & 14 & 35 & 19 \\
\hline 24 & 62 & $\mathrm{~F}$ & No & 36 & Medium & 11 & 33 & 14 \\
\hline 25 & 48 & M & Yes & 5 & Small & 19 & 35 & 16 \\
\hline 26 & 53 & $F$ & Yes & 7 & Medium & 16 & 33 & 24 \\
\hline 27 & 59 & $\mathrm{~F}$ & Yes & 156 & Large & 28 & 18 & 24 \\
\hline 28 & 68 & $\mathrm{~F}$ & No & 6 & Medium & 12 & 35 & 31 \\
\hline 29 & 57 & $F$ & No & 24 & Medium & 12 & 35 & 18 \\
\hline 30 & 72 & $\mathrm{M}$ & No & 12 & Medium & 11 & 35 & 14 \\
\hline 31 & 72 & $F$ & No & 7 & Medium & 12 & 35 & 19 \\
\hline
\end{tabular}

${ }^{\star}$ Time elapsed between the start of the symptoms and the surgical procedure.

involvement) was used. The tendons were reinserted by means of transosseous suture, acromioplasty was performed and the deltoid was reinserted in the acromion. The arm was immobilized in a Velpeau sling for six weeks and passive movement of the shoulder was started on the 15 th day after the operation. After six weeks, the patients were released from using the sling and referred to a physiotherapist.

Arthroscopic repair: The patients were under general anesthesia in association with brachial plexus block, in lateral decubitus. Anterior, lateral and posterior portals were used. A complete inventory of the glenohumeral 
joint was done routinely. Following this, bursectomy was performed to identify the size of the lesion and the tendons involved. In all cases, economical debridement of the edges of the lesion was performed and the rotator cuff reinsertion zone was prepared in a juxta-articular position. The tendons were reinserted using $5.0 \mathrm{~mm}$ titanium anchors in a single line with separations of $1.0 \mathrm{~cm}$ between each other, and using non-absorbable thread. Acromioplasty was performed when it was found that the subacromial space was greatly reduced due to a curved or hook-shaped acromion, or in cases of fibrillation of the coracoacromial ligament. Only in the cases of six patients was this not done: patients 4 , $5,8,13,18$ and 26 (group II). The long head of the biceps was tenotomized in two patients (patients 1 and 30; group II), and no tenodesis was done. The distal clavicle was also resected in one patient (patient 10; group II), because painful acromioclavicular arthrosis was presented. The postoperative care included protection of the repair by means of Velpeau sling for six weeks. Passive exercises for the shoulder were started four weeks after the surgery. After removal of the sling, the patients were referred for physiotherapy.

Statistical analysis: Statistical analysis was performed with a significance level of 5\%, using the SPSS software (Statistical Package for the Social Sciences, SPSS Inc., Chicago, IL, USA), version 17.0. The Mann-Whitney test was used for scalar variables, Fisher test for categorical variables and likelihood ratio for variations between groups.

\section{RESULTS}

The two groups were statistically similar regarding: sex $(p=0.474)$, age $(p=0.847)$, time elapsed between the start of symptoms and the treatment $(p=0.135)$, preoperative UCLA $(p=0.089)$ and postoperative UCLA $(p=0.553)$. They were also similar in relation to distribution according to size of lesion $(p=0.436)$.

According to the UCLA score, the results were considered to be thus: excellent (35-34 points), good (33-29 points), fair (28-21 points) or poor (20 points or less).

In group I (open repair), 27 patients (93.1\%) presented good/excellent results, with a mean postoperative UCLA score of 32. All the three patients with small lesions presented good/excellent results, and none of them presented renewed tearing on ultrasound. Out of the 12 patients with medium-sized lesions, $10(83.3 \%)$ presented good/excellent results and two (16.7\%) presented unsatisfactory results, with postoperative UCLA of 27 and 20, respectively (patients 4 and 14; group I) and signs of renewed tearing on ultrasound. All the 14 patients with large lesions had good/excellent results, although one $(7.7 \%)$ presented renewed tearing on ultrasound (patient 27; group I).

In group II (arthroscopy), 29 patients (93.5\%) presented good/excellent results, with mean postoperative UCLA of 33. Among the seven patients with small lesions, six (85.7\%) had good/excellent results and one (14.3\%) presented an unsatisfactory result (patient 12; group II), with postoperative UCLA of 16. This patient's ultrasound did not show any renewed tearing, but this case evolved with loosening of the anchor (Figure 1). All the 11 patients with mediumsized lesions presented good/excellent results, and none of them showed renewed tearing on ultrasound. Among the 13 patients with large lesions, $12(92.3 \%)$ presented good/excellent results and only two (15.4\%) presented renewed tearing on ultrasound (patients 9 and 27; group II), although one of them (7.7\%) had an UCLA score of 35 (patient 9; group II).

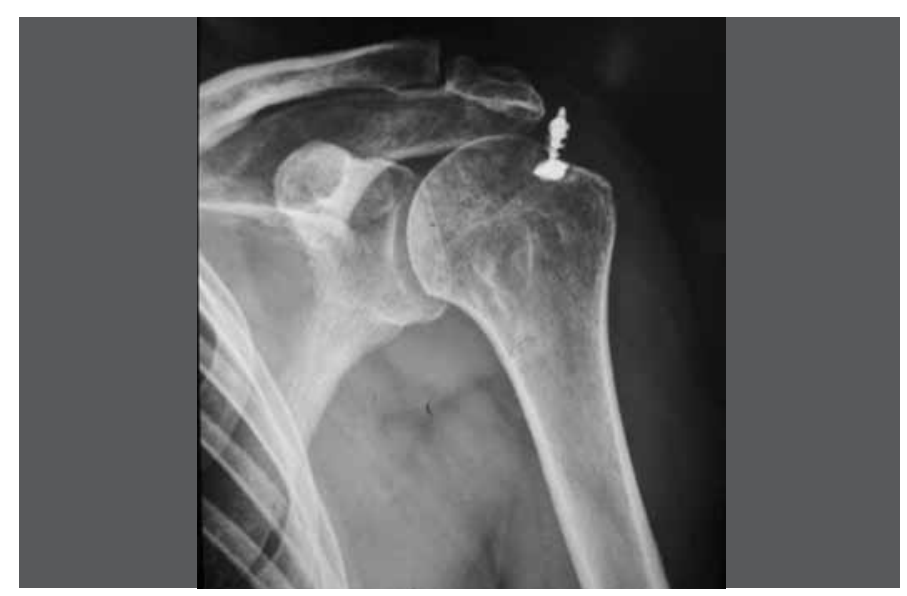

Figure 1 - X-ray in AP view of left shoulder of patient who underwent arthroscopic repair rotator cuff lesion (patient 12, group II), showing loosening of anchor (see text).

Source: Authors' personal files.

The number of postoperative complications was the same in the two groups: three cases of renewed tearing in the open group and two cases of renewed tearing and one case of loosened anchors in the arthroscopy group. No cases of infection were identified in either of the groups. 
Analysis on the influence of traumatic or degenerative origins of the lesion on the patients' final prognosis did not show any statistically significant differences, either in group I $(p=0.532)$ or in group II $(p>0.999)$.

Furthermore, according to the rotator cuff measurements, the size of the lesion did not influence the final result from the procedure, either in comparisons within the same group $(p=0.154$ in group I and $p=0.361$ in group II) (Table 3) or in comparisons of the same lesion pattern with different types of surgical approach.

There was no statistical difference in the final results between the two repair techniques used, as represented by UCLA score $>28(\mathrm{p}>0.999)$ (Table 4$)$.

Table 3 - Application of the likelihood test for comparison between the size of the lesion and the final result (UCLA) within each group separately.

\begin{tabular}{|c|c|c|c|c|c|}
\hline \multirow{2}{*}{ Group } & \multirow{2}{*}{$\begin{array}{l}\text { Size of } \\
\text { lesion }\end{array}$} & \multicolumn{2}{|c|}{ UCLA } & \multirow{2}{*}{ Total } & \multirow{2}{*}{$\begin{array}{c}\text { Significance } \\
(p)\end{array}$} \\
\hline & & $\leq \mathbf{2 8}$ & $>28$ & & \\
\hline \multirow{8}{*}{ Open repair } & \multirow{2}{*}{ Large } & 0 & 14 & 14 & \multirow{6}{*}{0.154} \\
\hline & & $0.00 \%$ & $100.00 \%$ & $100.00 \%$ & \\
\hline & \multirow{2}{*}{ Medium } & 2 & 10 & 12 & \\
\hline & & $16.70 \%$ & $83.30 \%$ & $100.00 \%$ & \\
\hline & \multirow{2}{*}{ Small } & 0 & 3 & 3 & \\
\hline & & $0.00 \%$ & $100.00 \%$ & $100.00 \%$ & \\
\hline & \multirow{2}{*}{ Total } & 2 & 27 & 29 & \\
\hline & & $6.90 \%$ & $93.10 \%$ & $100.00 \%$ & \\
\hline \multirow{8}{*}{ Arthroscopy } & \multirow{2}{*}{ Large } & 1 & 12 & 13 & \multirow{6}{*}{0.361} \\
\hline & & $7.70 \%$ & $92.30 \%$ & $100.00 \%$ & \\
\hline & \multirow{2}{*}{ Medium } & 0 & 11 & 11 & \\
\hline & & $0.00 \%$ & $100.00 \%$ & $100.00 \%$ & \\
\hline & \multirow{2}{*}{ Small } & 1 & 6 & 7 & \\
\hline & & $14.30 \%$ & $85.70 \%$ & $100.00 \%$ & \\
\hline & \multirow{2}{*}{ Total } & 2 & 29 & 31 & \\
\hline & & $6.50 \%$ & $93.50 \%$ & $100.00 \%$ & \\
\hline
\end{tabular}

Table 4 - Application of Fisher's exact test for comparison of the final results between the groups, based on postoperative UCLA scores.

\begin{tabular}{c|c|c|c}
\hline \multirow{2}{*}{ Group } & \multicolumn{2}{|c|}{ UCLA } & \multirow{2}{*}{ Total } \\
\cline { 2 - 4 } & $\mathbf{2 8}$ & $\mathbf{2 8}$ & \\
\hline \multirow{2}{*}{ Open repair } & 2 & 27 & 29 \\
\cline { 2 - 4 } & $6.90 \%$ & $93.10 \%$ & $100.00 \%$ \\
\hline \multirow{2}{*}{ Arthroscopy } & 2 & 29 & 31 \\
\cline { 2 - 4 } & $6.50 \%$ & $93.50 \%$ & $100.00 \%$ \\
\hline \multirow{2}{*}{ Total } & 4 & 56 & 60 \\
\cline { 2 - 4 } & $6.70 \%$ & $93.30 \%$ & $100.00 \%$ \\
\hline
\end{tabular}

\section{DISCUSSION}

Arthroscopic repair of rotator cuff injuries has become a current trend because this is a less invasive procedure $^{(1,4,5,15-17)}$. The lower levels of bleeding, lower morbidity, possibility of inspection of the joint for associated lesions and low complication rate from this technique ${ }^{(6,7,10,18)}$, along with the lower levels of postoperative pain ${ }^{(1,6,10,14,18,19)}$, can be highlighted. The results obtained have been satisfactory $(1,4,6,7,10,16,18)$, despite higher rates of renewed tearing ${ }^{(2,13,20)}$, biomechanically weaker fixation ${ }^{(13)}$, higher cost and nee for a longer learning curve $\mathrm{c}^{(4,10,16,17)}$.

Open repair has also provided good results ${ }^{(2,3,13,17)}$, and enables excellent viewing of the cuff ${ }^{(1,2)}$, but it presents greater risks of complications such as dehiscence of the deltoid, infection, arthrofibrosis and pain ${ }^{(1,4,6,7,18,21)}$.

In our study, no cases of infection, suture dehiscence, deinsertion of the deltoid or neurovascular lesion were detected. Moreover, the numbers of cases of renewed tearing were similar. However, it need to be mentioned that the postoperative protocol used was different for the two groups, such that in the open group, passive exercises for the shoulder were started 15 days after the operation, whereas in the arthroscopy group, they were only started 28 days after the operation. We started passive movement earlier in the open group because of concern regarding development of capsulitis, and later in the arthroscopy group in order to minimize the possibility of renewed tearing. This difference may have influenced the final results.

Recent studies have shown high numbers of cases of renewed tearing of tendons operated using both techniques $^{(2,8,11,17)}$, and that these numbers seem to increase as the size of the lesion increases ${ }^{(8,13,17)}$. These data were not confirmed in our study, in which there was a total of five cases $(8.3 \%)$ of renewed tearing, and these could not be correlated with the size of the lesion.

The aims in repairing the rotator cuff are to relieve pain and reestablish functional ability $(13,20)$. In our study, we achieved good/excellent results in more than $90 \%$ of the patients in both groups, a rate that is similar to what has been found in the literature $(11,13,17)$. In all the patients, an improvement in UCLA score was observed, even in those who presented renewed tearing on ultrasound, except for one case (patient 27; group II). This patient presented a large lesion, with the first report of symptoms 13 years earlier, and MRI showed that significant retraction of the stumps had taken place, with 


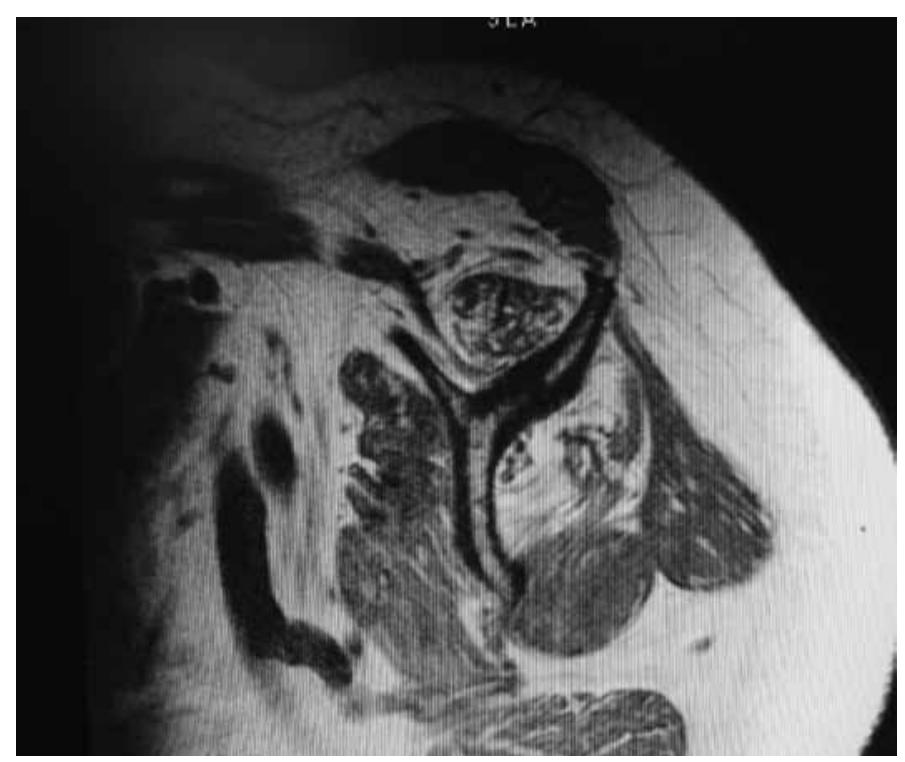

Figure 2 - Sagittal T1-weighted magnetic resonance image of left shoulder, showing atrophy and fatty degeneration of the supra and infraspinatus tendons.

Source: Authors' personal files.

Goutalier grade III fatty infiltration ${ }^{(22-24)}$ (Figure 2). During the operation on this patient, total closure of the lesion was achieved, but under tension, which may have influenced the renewed tearing. Some authors have reported that there was greater incidence of renewed tearing in larger lesions (big and extensive) than in small and mediumsized lesions ${ }^{(11,25,26)}$.

One patient presented loosening of an anchor (patient 12; group II), even though the lesion was small. This was a 64-year-old patient with a reported start of symptoms three years before the surgery, without any history of trauma. The loosening may have occurred because of an error in positioning the anchor because of poor bone quality. This patient required a new surgical approach, this time using open access, with removal of the anchor and the tendon-bone suture.

We did not find any statistical difference in the final results between the patients who underwent open repair (93.1\% good/excellent) and those who underwent arthroscopy (93.5\% good/excellent) on the rotator cuff lesions. Despite the short follow-up period and the relatively small number of patients in our sample, our results are concordant with the current literature $^{(7,9,10,13-15,19)}$. There was no direct statistical correlation between the size of the lesion and the final result ( $p>0.999$; Table 4), which was also observed by Henrique $^{(3)}$.

Another factor that may have influenced our results was the homogeneity between the groups in relation to the number of individuals in each group, their ages, sex, pre and postoperative UCLA and the sizes of the lesions. We can also highlight that the short follow-up time in our study was one of the factors that influenced the result. The minimum follow-up time was 12 months, but some authors have demonstrated deterioration of the results over the long term ${ }^{(2,8,25,27)}$.

Regarding acromioplasty, this was done on all the patients in the open group in order to make it easier to access the torn tendons. In the arthroscopy group, this was only done when the subacromial space was shown to be tight, with presentation of fibrillation and erosion of the coracoacromial ligament. In both situations, there was no influence on the functional results, and this finding was concordant with those of Gartsman \& O'Connor ${ }^{(28)}$ and Veado et $a l^{(2)}$.

In the patients in whom tenotomy of the long had of the biceps was performed, there were no abnormalities in the functional results, which was also reported by Checchia et $a l^{(29)}$.

The presence of acromioclavicular arthrosis is a frequent finding in MRI examination. However, this should only be given value and treated when there is a clinical correlation ${ }^{(2,6,28)}$. In the present sample, resection of the distal clavicle was only necessary in one patient (patient 10; group II), who evolved with a postoperative UCLA score of 33 .

It needs to be emphasized that all the patients in this study came from the same public service, with similar characteristics among them; they were all operated by the same surgeon; and the postoperative ultrasound examinations were performed by only two specialists at the same service, using the same apparatus. This increases the likelihood that the results will be similar, whether good or poor.

\section{CONCLUSION}

We therefore conclude that the repairs on rotator cuff injuries presented good results by means of both open surgery and arthroscopy, independent of the size of the lesion (small, medium or large) with similar functional results in the two groups and similar rates of renewed tearing after a minimum follow-up of 12 months.

\section{ACKNOWLEDGEMENTS}

We are grateful to Dr. Diamantino Lobo for his help in data gathering and patient assessments. 


\section{REFERENCES}

1. Andrade RP, Correa Filho MRC, Queiroz BC. Lesões do manguito rotador. Rev Bras Ortop. 2004;39(11/12):621-36.

2. Veado MAC, Gomes TPO, Pinto RZA. Análise funcional e estrutural do reparo das lesões extensas do manguito rotador. Rev Bras Ortop. 2006;41(8):294-301.

3. Henrique A. Avaliação pós-operatória de 206 reparações cirúrgicas abertas em roturas de manguitos rotadores. Rev Bras Ortop. 2003;38(8):480-90.

4. Veado MAC, Filho IAA, Duarte RG, Leitão I. Avaliação funcional do reparo artroscópico das lesões completas do manguito rotador associado a acromioplastia. Rev Bras Ortop. 2008;43(11/12):505-12.

5. Godinho GG, Freitas JMA, França FO, Filho JSA, Schio C, Júnior SCP. Estudo da vascularização das bordas das lesões nas roturas completas do manguito rotador. Rev Bras Ortop. 2007;42(6):169-72.

6. Checchia SL, Doneux Santos P, Miyasaki AN, Fregoneze M, Silva LA, Ishi M, et al. Avaliação dos resultados obtidos na reparação artroscópica das lesões do manguito rotador. Rev Bras Ortop. 2005;40(5):229-38.

7. Miyasaki AN, Fregoneze M, Doneux Santos P, Silva LA, Pinto ECMM, Ortiz RT, et al. Lesões extensas do manguito rotador: avaliação dos resultados do reparo artrocópico. Rev Bras Ortop. 2009;44(2):148-52.

8. Checchia SL, Doneux Santos P, Miyasaki AN, Fregoneze M, Silva LA, Mussi S, et al. Tratamento cirúrgico das lesões extensas do manguito rotador pela via de acesso deltopeitoral. Rev Bras Ortop. 2003;38(5):252-60.

9. Millstein ES, Snyder SJ. Arthroscopic management of partial, full-thickness and complex rotator cuff tears: indications, techniques, and complications. Arthroscopy. 2003;19 Suppl 1:189-99.

10. Park JY, Chung KT, Yoo MJ. A serial comparison of arthroscopic repairs for partial- and full-thickness rotator cuff tears. Arthroscopy. 2004;20(7):705-11.

11. Cole BJ, McCarty LP 3rd, Kang RW, Alford W, Lewis PB, Hayden JK. Arthroscopic rotator cuff repair: prospective functional outcome and repair integrity at minimum 2-year follow-up. J Shoulder Elbow Surg. 2007;16(5):57985.

12. Cofield RH, Parvizi J, Hoffmeyer PJ, Lanzer WL, Ilstrup DM, Rowland CM. Surgical repair of chronic rotator cuff tears. A prospective long-term study. J Bone Joint Surg Am. 2001;83(1):71-7.

13. Bishop J, Klepps S, Lo IK, Bird J, Gladstone JN, Flatow EL. Cuff integrity after arthroscopic versus open rotator cuff repair: a prospective study. J Shoulder Elbow Surg. 2006;15(3):290-9.

14. Buess E, Steuber KU, Waibl B. Open versus arthroscopic rotator cuff repair: a comparative view of 96 cases. Arthroscopy. 2005;21(5):597-604.
15. Burns JP, Snyder SJ. Arthroscopic rotator cuff repair in patients younger than fifty years of age. J Shoulder Elbow Surg. 2008;17(1):90-6.

16. Gartsman GM, Khan M, Hammerman SM. Arthroscopic repair of full-thickness tears of the rotator cuff. J Bone Joint Surg Am. 1998;80(6):832-40.

17. Youm T, Murray DH, Kubiak EN, Rokito AS, Zuckerman JD. Arthroscopic versus mini-open rotator cuff repair: a comparison of clinical outcomes and patient satisfaction. J Shoulder Elbow Surg. 2005;14(5):455-9.

18. Almeida A, Valin MR, Almeida NC, Ferreira R. Avaliação da dor pós-sutura artroscópica do manguito rotador. Rev Bras Ortop. 2006;41(9):341-6.

19. Shinoda T, Shibata Y, Izaki T, Shitama T, Naito M. A comparative study of surgical invasion in arthroscopic and open rotator cuff repair. J Shoulder Elbow Surg. 2009;18(4):596-9.

20. Neri BR, Chan KW, Kwon YW. Management of massive and irreparable rotator cuff tears. J Shoulder Elbow Surg. 2009;18(5):808-18.

21. Herrera MF, Bauer G, Reynolds F, Wilk RM, Bigliani LU, Levine WN. Infection after mini-open rotator cuff repair. J Shoulder Elbow Surg. 2002;11(6):605-8.

22. Goutallier D, Postel JM, Bernageau J, Lavau L, Voisin MC. Fatty muscle degeneration in cuff ruptures. Pre-and postoperative evaluation by CT scan. Clin Orthop Relat Res. 1994;(304):78-83.

23. Goutallier D, Postel JM, Bernageau J, Lavau L, Voisin MC. Fatty infiltration of disrupted rotator cuff muscles. Rev Rhum Engl Ed. 1995;62(6):415-22.

24. Goutallier D, Postel JM, Gleyze P, Leguilloux P, Van Driessche S. Influence of cuff muscle fatty degeneration on anatomic and functional outcomes after simple suture of full-thickness tears. J Shoulder Elbow Surg. 2003;12(6):550-4.

25. Galatz LM, Ball CM, Teefey SA, Middleton WD, Yamaguchi K. The outcome and repair integrity of completely arthroscopically repaired large and massive rotator cuff tears. J Bone Joint Surg Am. 2004;86(2):219-24.

26. Sugaya H, Maeda K, Matsuki K, Moriishi J. Functional and structural outcome after arthroscopic full-thickness rotator cuff repair: single-row versus dual-row fixation. Arthroscopy. 2005;21(11):1307-16.

27. Lee E, Bishop JY, Braman JP, Langford J, Gelber J, Flatow EL. Outcomes after arthroscopic rotator cuff repairs. J Shoulder Elbow Surg. 2007;16(1):1-5.

28. Gartsman GM, O'connor DP. Arthroscopic rotator cuff repair with and without arthroscopic subacromial decompression: a prospective, randomized study of one-year outcomes. J Shoulder Elbow Surg. 2004;13(4):424-6.

29. Checchia SL, Doneux PS, Miyazaki AN, Silva LA, Fregoneze M, Ossada A, et al. Biceps tenodesis associated with arthroscopic repair of rotator cuff tears. J Shoulder Elbow Surg. 2005;14(2):138-44. 